Dr Verrier. Thank you. I also think the effect of the reoperation that occurs cannot be understated because certainly most of us have abandoned the homograft except in endocarditis because when you have to reoperate on a calcified root in a young person, it is one of the most daunting operations we perform.

Dr Dagenais. I totally agree.

Dr D. Craig Miller (Stanford, Calif). Francois, nice presentation, but I cannot let you get away with censoring all these "noncardiac deaths." I know you did not have autopsies, or did you? How do you know that those 18 deaths, a lot of which were probably sudden and unexplained, were not of a cardiac cause? That has been a bugaboo in any valve series, and the only way to conservatively approach it is to consider them all, knowing that you are probably overestimating the incidence of cardiac death, but at least you are not letting something that smells bad creep into your data. What would those curves look like with all deaths?

Dr Dagenais. We are the only center to which 3 million persons are referred, and we have 2 nurses who are truly dedicated to follow these patients. Most of these patients have autopsies when they die. I think in such circumstances it is difficult to keep the noncardiac deaths in the analysis considering the age difference between the groups. This is, however, a study limitation. When you include the noncardiac deaths, there was a trend toward lower survival in the Freestyle and the stented xenograft groups.

\title{
ON THE MOVE?
}

Don't miss a single issue of the journal! To ensure prompt service when you change your address, please photocopy and complete the form below.

Please send your change of address notification at least six weeks before your move to ensure continued service. We regret we cannot guarantee replacement of issues missed due to late notification.

\section{JOURNAL TITLE:}

Fill in the title of the journal here.

OLD ADDRESS:

Affix the address label from a recent issue of the journal here.

\section{NEW ADDRESS:}

Clearly print your new address here.

Name

Address

City/State/ZIP
COPY AND MAIL THIS FORM TO:

Elsevier Inc.

Subscription Customer Service

6277 Sea Harbor Dr

Orlando, FL 32887
OR FAX TO:

407-363-9661

OR E-mail:

elspcs@elsevier.com
OR PHONE:

800-654-2452

Outside the U.S., call

407-345-4000 